\title{
A forma da música em Film Socialisme de Jean-Luc Godard
}

José Eduardo Costa Silva (UFES)

Resumo: Este artigo traz uma reflexão filosófica sobre a música de "Film Socialisme" de Jean-Luc Godard: a sinfonia, a forma canção e a paisagem sonora na poética cinematográfica de Godard. É um estudo sobre a proposição de que a música se configura como um componente formal e estrutural de uma obra cinematográfica, realizando-se como pensamento.

Palavras-chave: Música de filme; forma; Film Socialism; filosofia.

THE MUSIC FORM IN FILM SOCILIASME BY JEAN-LUC GODARD

Abstract: This paper is a philosophical consideration about the music in Jean-Luc Godard's movie Film Socialisme. In Godard's cinematographic poetic it is considered the symphony, lied form and soundscape. It is a study on the proposition that music is a formal and structural component of the movie, becoming itself a thought.

Keywords: Movie's music; form; Film Socialisme; Philosophy. 


\section{Introdução}

No início do séc. XX generaliza-se a crítica aos paradigmas que no passado permitiram o erguimento da Filosofia Clássica e da Epistemologia Moderna. Primeiro Frege. A seguir Wittgenstein com seu célebre Tractatus LogicoPhilosophicus; ambos lançaram argumentos suficientes para sustentar a opinião de que interrogação sobre o ser e sobre o sujeito do conhecimento teriam levado o pensamento ao limite inatingível da linguagem. O que estava em dúvida agora era a linguagem, que tornou possível o erguimento do conhecimento filosófico e científico, aos quais estiveram relacionados em sua gênese os grandes projetos políticos e econômicos da humanidade; dentre eles: o Capitalismo e o Socialismo.

Crise paradigmática, o mesmo que crise da filosofia e da ciência, o mesmo que crise dos grandes esquemas explicativos que sustentam ideologicamente os grandes projetos políticos. Desse modo, a contemporaneidade reedita o dilema outrora vivido pelos gregos e que esteve latente no percurso histórico da filosofia, qual seja, buscar possíveis fundamentos para conhecimento ou manter-se no relativismo. Não por acaso Platão interrogou a linguagem no célebre diálogo Crátilo, discutindo questões comuns aos seus contemporâneos e à atual Filosofia da Linguagem: o que a linguagem permite dizer ou conhecer? Há relação entre palavras e coisas? O que se dá aos sentidos corresponde ao que dele se fala? Há adequação entre o intelecto e coisa por ele pensada? Também, não por acaso, tais questões participam da temática de Film Socialisme. O filme de Godard pretendese retrato de seu próprio contexto; suas narrativas conclamam que a linguagem é

\footnotetext{
${ }^{1}$ A) Refiro-me nesse parágrafo à crise paradigmática que alastrou-se e generalizou-se no início do séc. XX, atingindo praticamente a todas as áreas do conhecimento e que, dentre outras consequências, promoveu a linguagem a paradigma filosófico e também possibilitou a estruturação de uma corrente contemporânea da filosofia denominada Filosofia da Linguagem. Participam direta ou indiretamente desta corrente filosófica pensadores tais como Frege, Wittgenstein, Austin, Habermas. B) Emprego o termo paradigma no sentido de ele tratar-se de uma questão que inaugura um modo específico de filosofar. Por exemplo, paradigma do ser (ontológico): o que é o ser? Paradigma epistemológico: como e quanto o sujeito pode conhecer? C) Filosofia Clássica; refiro-me à Filosofia Grega de Platão, Aristóteles, dentre outros, que propuseram paradigmaticamente a interrogação sobre o ser. Epistemologia Moderna; refiro-me aos esquemas explicativos da modernidade (séc. $\mathrm{XVI} / \mathrm{XVIII}$ ), quais foram os de Descartes e Kant, dentre outros, que propuseram paradigmaticamente a interrogação sobre o sujeito do conhecimento.
} 
falível e insuficiente. Por isso, falar de Film Socialisme é falar de seu contexto. E o mesmo cuidado metodológico há de servir à discussão sobre sua música.

Contudo, quando impera a dúvida sobre a possibilidade da linguagem aceder ao conhecimento, quando estão em dúvida os esquemas explicativos produzidos por diversas correntes da filosofia, o desejo de encontrar um plano conceitual para a compreensão e elaboração da música de filme pode parecer inútil. Certamente, a música de filme é como outra qualquer, e como tal está circundada pelos mesmos impasses teóricos; a descrença geral ante ao conhecimento recai também sobre a área do conhecimento musical. Logo, o apelo para que nos concentremos em estudos de situações particulares é forte, confirmando deste modo a tendência contemporânea a fragmentar o conhecimento. Arriscar-se na elaboração de um plano conceitual que ultrapasse a particularidade empírica, tal como fora a práxis do filosofar tradicional, põe em risco a credibilidade do cientista, do filósofo e do músico que se dispõe a falar de sua atividade.

A música de filme é como outra qualquer e até mesmo quando está diretamente orientada para o mercado fonográfico das trilhas há de ter seu sentido vinculado a uma obra cinematográfica. A propósito, esta constatação é válida para qualquer tipo de música de cena. Então é de se perguntar se a compreensão da música de filme está necessariamente e empiricamente condicionada à particularidade da obra em que está inserida. O risco é conhecido por todos: o procedimento que é sucesso em um filme pode se converter em clichê em outro. Por isso, associações corriqueiras entre música e cena, tais como a associação entre dissonância e medo, converteram-se em clichê ou, porque não dizer, em "cânones" poético e estético.

Entretanto, dois sentidos gerais de interrogação e compreensão da música de filme se impõem, apesar da dificuldade apontada de se encontrar um plano conceitual que ultrapasse a particularidade da empiria; são eles: 1) os que identificam modos em que a música sustenta e afirma as situações em que ela se insere, 2) os que identificam as relações dialógicas entre música e cena, nas quais, 
por vezes, a música nega a cena, para afirmar-se em sua dimensão de autonomia. Mesmo reconhecendo a relevância de se estudar uma vez mais e sempre esses dois sentidos, proponho, para o presente artigo, a reflexão sobre um terceiro sentido que tem sido experimentado por diretores de cinema de diversas escolas: a interrogação sobre possíveis relações formais e estruturais entre música e filme.

A ideia de estruturar filmes segundo modelos formais provenientes da música é recorrente. Akira Kurosawa (Rapsódia de Outono) e Bergman (Sarabande), por exemplo, participam de uma lista de diretores que tem se esforçado para aperfeiçoá-la. Mas chamou-me a atenção o modo como ela se concretizou em Film Socialisme de Jean-Luc Godard, a ponto de, em alguns momentos, aventar a hipótese de que esse filme inaugure um outro gênero artístico, que mereça o nome de música-cinema ou vice-versa. Afora a beleza e o sucesso poético experimentados por Godard, impõe-se como objeto de investigação as articulações entre música e imagem que buscam responder às questões trazidas pela descrença na linguagem e no conhecimento.

Trata-se, eis o teor da argumentação que desenvolvo, de apresentar a música como a estrutura de um pensamento que, em determinados momentos, substitui eficazmente o pensamento que está posto em dúvida pela atualidade. E tudo isso é colocado com clareza, posto que os procedimentos de articulação entre música e imagem utilizados por Godard são facilmente identificáveis. Portanto, Film Socialisme é um objeto de estudo que pode paradigmaticamente sustentar proposições gerais, a começar pelo reconhecimento de que existe o apontado terceiro sentido de interrogação da música de filme.

Os referenciais teóricos que norteiam o presente texto aparecem na ordem em que dialogam com as questões trazidas pelo filme. Pouco a pouco vêm à presença os pensamentos de Aristóteles, Heidegger, Marx, Nietzsche, Alain Badiou, dentre outros. Trata-se de um procedimento metodológico que entrega o pensamento ao vigor e dinamicidade de uma obra-prima, que solicita a máxima atividade de um sujeito do gozo e do conhecimento, tal é o caso de Film Socialisme de Jean-Luc Godard. 


\section{I- A matéria do filme: um pensamento sobre a linguagem e um mundo fragmentados.}

Film Socialisme é feito de signos fragmentários que tendem a se tornarem anônimos na desmemoria. Sua matéria é um convite à decifração do enigma poético que se ergue a partir dela e que se mostra na disposição dos créditos editados no DVD. ${ }^{2}$ Sem que títulos sejam citados, mencionam-se textos de Benjamin, Derrida, Curnier, Dubillard, Arendt, Bismarck, Sartre, Brunschwig, Giraudoux, Tardieu, Peguy, Aragon, Rullac, Bergson, Bernanos, Rougemont, Wolff, Korsakov, Braudel, Simon, Gabler, Pirandello, Ricouer, Beckett, Malraux, Levi-Strauss, Conrad, Shakespeare, Heidegger, Rochefoucauld, Goethe, Malaparte, J. Genet, Oldenbourg. E também obras musicais de Betty Olivero, Arvo Pärt, Anouar Brahem, Tomasz Stanko, Bernd Alois Zimmermann, Giya Kancheli, Werner Pirchner, E. Busch, Thierry Machuel, Ludwig Van Beethoven, Chet Baker.

Acrescentam-se fragmentos de vídeos que retratam pessoas e lugares históricos e vídeos originais, filmados em câmeras de celular, vídeo digital padrão, vídeos de alta definição (Ebert, 2011). Ruídos em profusão; ruídos da produção das imagens, o barulho pronunciado do vento que toca o navio e o microfone das câmaras. Há, sobretudo, o silêncio que se insinua entre os cortes das tomadas em sequência, entre interrupções de falas, nas defasagens e perdas de sincronia entre som e imagem. A propósito, as legendas sugeridas por Godard não correspondem necessariamente e inteiramente ao texto falado, e, algumas delas não possuem verbo ser e estar ou qualquer partícula de ligação. ${ }^{3}$

Film Socialisme é uma colagem em que os signos se interligam mais por proximidade do que por relações causais. Como dizem as palavras que

\footnotetext{
${ }^{2}$ A ficha técnica do filme está no Anexo I, ao final do artigo.

3 Tratam-se de "stubs telegrammatic" que visam apresentar determinado significado sintetizado em aproximadamente duas ou três palavras. Às vezes, elas apresentam uma espécie de "anti" neologismo que consiste simplesmente na junção de palavras em uma só, onde o som resultante é a negação de um sentido originário. Por exemplo: nãoágua; nãorelógio (DVD, Cap. 1).
} 
segmentam o filme: Des choses / comme ça. "Essas coisas?" "As coisas assim?" "As coisas em seu aí" - simplesmente jogadas em sua existência mundana? Entretanto, a colagem de Godard não é mera colagem, como muitas que, sob o vago qualificativo de obras pós-modernas, estão expostas nas galerias e museus. Permeia sua matéria, como uma espécie de liga fina, a questão que impulsiona um pensamento, qual seja: como viver em um mundo que proclama o fracasso de uma tradição do pensamento que não pôde se converter em um estado satisfatório de vida? Desdobrando a questão; como viver em um mundo sem grandes esquemas explicativos, sem teorias, sem metafísica, sem iluminismo, enfim, sem projetos coletivos, sem socialismo?

Film Socialisme pensa a ausência do socialismo; a dissolução de um projeto coletivo que parece sucumbir ante suas próprias contradições e, principalmente, ante a lógica do capital que transforma a tudo e a todos em meras coisas. E desse modo ele se inscreve na discussão sobre a descrença nos grandes esquemas explicativos. É ilustrativo; Alain Badiou, o filósofo que no filme faz papel de si mesmo, discursa sobre a geometria. Aparentemente nenhuma ligação com a temática proposta; aparentemente! Posto que é de se pensar no episódio da fundação da Analítica Contemporânea, decorrente da crítica à Geometria Euclidiana, por parte de G. Frege (Blanchete, 2012). Em síntese, a crítica à Geometria Euclidiana, um dos fundamentos da metafísica, esvaziou o sentido tradicional do filosofar, qual seja, a indagação sobre o ser e o conhecimento. A partir de então, impôs-se como paradigma o questionamento à própria linguagem sobre a qual se erguera o patrimônio filosófico ocidental (Badiou, 1990, p. 3644).

Quo Vadis Europa? A ironia de uma frase épica. Da crise dos grandes sistemas explicativos e projetos coletivos à dúvida sobre a linguagem; a questão do Crátilo de Platão vigora: há relação entre as palavras e as coisas? Na tela do cinema, assim como na tela do computador de uma das personagens, dois gatinhos pronunciam melopeia de papagaios. Apenas melopeia? Significante dissociado de significado? Significantes puros? (Lacan, 1998, p. 24). Em sua origem, a palavra é som. Na falta da linguagem, a música? Ironicamente, a jovem 
intercepta as indagações de Badiou: “la geometria...lá? Dó-ré-mi-fá-sol-lá?” (DVD, Cap. 5)

Ocorrem à mente tradicionais proposições filosóficas sobre as relações entre música e filosofia: a música em sentido lato, antes da palavra, gemidos e grunhidos (Rousseau, 1999, p. 247); a mera forma universal, o signo vazio e prenhe do estado afetivo que acolhe a razão, condição metafísica da linguagem (Schopenhauer, 1969, p. 309); expressão da pulsão de Dioniso, dizer da totalidade que se individua em formas apolíneas, quais sejam as palavras e coisas designadas (Nietzsche, 2006, pr. 3/8). Em resumo, a noção de que a música é ontologicamente próxima ao universo afetivo é recorrente na tradição do pensamento. Desta noção decorre outra: a música é em si mesma a dimensão de não linguagem da linguagem, onde o silêncio polissêmico do universo afetivo é condição para o ato simbólico originário de todo dizer. Instaurando-se como eidos, a música é força evanescente do significante puro, a permanência da intenção de significar o que é em essência movimento dos afetos.

A música é o estar entre a palavra e a coisa (Heidegger, 2003, p. 24). 0 afeto transformado em movimento mélico que liga o saber imediato da coisa a seu signo. Mousikè, entre os gregos! Lógos! O dizer cantante do ser indeterminado que se determina como significado no ente (Heidegger, 2003, p. 27). Com sua força unificadora a música instaura uma afinação (Stimmung). Afinação, isto é, estar em uma tonalidade afetiva do ser, compartilhando um modo de significar o mundo (Heidegger, 1988, p. 29). A afinação instaurada pela música é estranha à afinação vigorante no cotidiano (facticidade), justamente a que corresponde à concepção habitual de que o ser é um composto de matéria e forma, segundo uma finalidade lógica (Vattimo, 1996, p. 17). Conquanto no cotidiano os entes sejam compreendidos como uma totalidade de úteis familiares, que funcionam e se estruturam logicamente de acordo com uma finalidade, sob a afinação da 
música impera a abertura do ser para o indeterminado polissêmico, no que constitui a sua estranheza. ${ }^{4}$

A estranheza da música sustenta o antifilme de Godard. ${ }^{5}$ Dá solo afetivo e contribui para a continuidade e unidade das imagens que não querem corresponder às palavras ou às câmeras; afirmação radical da Nouvelle Vague. Nada surpreendente, tratando-se de Godard, para quem o cinema sempre foi som e imagem, em vez de narrativa linear. ${ }^{6}$ Como observa Lorber, Godard não está preocupado apenas com a política, um dos temas de seu filme. Ele está preocupado com o modo como participamos da produção e consumimos sons imagens (Lorber, 2010). Por isso, a câmera é um dos ícones que aparece em todas as partes do filme, como se nós mesmos estivéssemos por trás dela, juntos com o cineasta e sua equipe, tentando em vão, capturar com imagens o devir da história, como turistas pós-modernos.

Em outros termos, a música sustenta o que no filme não está totalmente explicitado em imagens e palavras, revelando algo de sua essência: o sujeito na visão de si mesmo, na medida em que se vê em tensão com um mundo que se dissolve em fragmentos. Ainda, o sujeito que sente a ausência de uma grande história, que pode ser a história de seu país, de suas crenças e de seus projetos ideológicos. Não obstante, a música de Film Socialisme desempenha as funções de qualquer outra trilha sonora; a música reforça, descreve, colore, pontua, reporta

\footnotetext{
${ }^{4}$ No texto citado, Vattimo chama-nos a atenção para a crítica de Heidegger à Doutrina das Quatro Causas de Aristóteles, que leva-nos a concluir que o ser é um composto de matéria e forma. Heidegger é crítico da concepção finalista desta doutrina: "uma matéria assume uma forma para cumprir a função de...". Antes disso, Heidegger concebe que o ser é abertura para a multiplicidade da interpretação fenomênica da realidade e também para a indeterminação do acaso.

${ }^{5}$ Parece vigorar a ideia: sem socialismo, sem filme! Mais do que uma provocação, uma dúvida lançada sobre a linguagem e a arte em geral. A propósito, uma das possíveis interpretações para o título - Film Socialisme - é justamente de que se tratam de dois entes desconexos, sem ponto de contato.

${ }^{6}$ Refiro-me à filiação de Godard ao grupo de cineastas e críticos em torno da revista Cahiers Du Cinéma que ficou conhecido como Nouvelle Vague, que, dentre outros, reunia François Truffaut, Chabrol Claude e Jacques Rivette. Em linhas gerais, esse grupo se propôs a questionar a natureza do cinema e da câmera, considerando o impacto desses na subjetividade. Não se trata mais de "contar histórias" mas de flagrar com a câmera cotidiana o sujeito em sua vida de fatos aparentemente desconexos.
} 
simbolicamente a universos semânticos que às vezes vão além da presença da imagem. A música narra, descreve e emociona (Repetto, 2011, p. 37). Por outro lado, a música de Film Socialisme convive dialeticamente com os demais signos, às vezes discordando, às vezes comentando com ironia sutil, tal como preconizariam Adorno e Eisler. Reporto-me, por exemplo, à cena em que a mãe da "Família Martin" comenta com a filha sobre a ausência de um programa político ao som do Andante Cantabile (20 Mov) da Sonata N. 8, Op. 13 de Beethoven (A Patética) (DVD, Cap. 10). Justamente Beethoven, um dia declarado entusiasta do ideário da Revolução Francesa.

Contudo, além de desempenhar as funções tradicionais de uma trilha sonora, a música estrutura Film Socialisme. Configurada como uma totalidade polifônica que se constitui por fragmentos de obras musicais, textos em diversas línguas e ruídos de toda ordem, ela se faz onipresente e essencial a todo e qualquer evento significador. A propósito, é válida a observação de James Mônaco, para quem em um filme há mais elementos sonoros do que visuais (Monaco, 2000, p. 36). ${ }^{7}$ Certamente, esse fator é levado em consideração na poética de Godard que, como veremos a seguir, utiliza a música para dar forma ao que é muitas vezes desconexo, propiciando, inclusive, que sigamos trilhas de temas em um emaranhado de referências textuais e imagéticas fragmentárias. Como em um poema, as imagens de Film Socialisme solicitam a escuta.

\section{II- A música como estrutura de Film Socialisme ${ }^{8}$}

\section{1- Sinfonia e Canção}

\footnotetext{
${ }^{7}$ Em "How to Read a Film", James Monaco, citando Christian Metz, observa que um filme tem mais elementos sonorous de comunicação do que visuais, precisamente, na seguinte distribuição: 1) imagens; 2) grafismos; 3) diálogos; 4) música; 5) efeitos.

${ }^{8}$ Uma ideia abrangente da distribuição dos eventos sonoros e imagéticos de Film Socialisme é dada pelo quadro inscrito no Anexo II deste artigo.
} 
No encarte do DVD lê-se: "É a sinfonia em três movimentos de Godard." Efetivamente, tendo em vista sua macroestrutura, Film Socialisme é composto por três movimentos, entenda-se, três blocos temáticos facilmente discerníveis, não obstante as relações entre esses movimentos não sejam claras, sobretudo para um público pouco habituado à leitura de textos filosóficos e históricos. O primeiro movimento, Des choses comme ça (Essas coisas), se passa em um cruzeiro turístico, o "Costa Concórdia", destruído em Janeiro de 2012. Em uma travessia pelo Mar Mediterrâneo passageiros de diversas nacionalidades comportam-se como se suas vidas estivessem à deriva, limitando-se às atividades frívolas da programação de um navio desta natureza, nota-se, um ícone da sociedade contemporânea de consumo. Os ruídos desses passageiros contracenam com fragmentos de textos, ora ditos na língua de cada um, ora ditos em voz em off. Dentre esses passageiros, identifica-se um velho criminoso de guerra - Richard Christmann - auto apresentado como Otto Goldberg. Identificam-se também um ex-oficial da ONU, um detetive russo que procura o Ouro de Moscou e a cantora americana Patti Smith e, por fim, o filósofo Alain Badiou, que pronuncia um discurso sobre geometria na TV.

O segundo movimento, Notre Europe (Nossa Europa), se passa às margens de uma estrada, em um posto de gasolina. Na casa anexa ao posto, reside a "Família Martin". ${ }^{9}$ No contexto de uma campanha eleitoral, o casal de filhos desta família convoca seus pais a debaterem sobre os temas da liberdade, igualdade e fraternidade. O debate é perscrutado por uma jornalista e uma cinegrafista da FR3. O terceiro movimento, Nos Humanités (Nossas Humanidades) é um mosaico dinâmico, formado por imagens do Egito, Palestina, Odessa, Hellas, Nápoles e Barcelona. Tratam-se de lugares históricos e "lendários", na medida em que se referem às articulações entre realidade e ficção elaboradas por Godard, articulações conjecturais fundamentadas na verossimilhança. Por exemplo, pelos

\footnotetext{
${ }^{9}$ Vale a observação sobre os vários paralelos entre ficção e realidade encontrados em Film Socialisme. A Família Martin é também o nome de uma organização política da região de Colmar, encarregada de encaminhar pelo Vosges e depois pela fronteira suíça, os prisioneiros de guerra e desertores alsacianos. Curiosamente, o segundo movimento do filme é filmado em uma garagem suíça, ao lado de rolle (Mas \& Pisani, 2010).
} 
lugares referidos teria supostamente passado o "ouro de Moscou" que, no filme, é investigado pelo detetive russo. Em outra situação, fragmentos de vídeos destacam as escadarias de Odessa, espécie de emblema de um destino trágico que, um dia encenado no Encouraçado Potemkin, filme de Eisenstein que guia as reflexões de Godard, subsiste na atualidade como monumento turístico.

Entretanto, é de se perguntar até que ponto essa segmentação corresponde ao que correntemente denominamos com o termo "sinfonia". De que período histórico seria a sinfonia de Godard? De que estilo? De que sinfonia em particular falamos? Há de se evocar o significado mais genérico que o termo sinfonia recebeu em fins do renascimento e início do barroco europeus; tal como as sonatas, as sinfonias seriam simplesmente "música feita para soar", sem necessário compromisso com palavras e imagens. A música em sua afirmação mais ingênua, que não reclama para si associações de significação, salvo intenções posteriores de músicos e ouvintes.

Por outro lado, não há propriamente em Film Socialisme o esforço de um movimento de contraditórios que marcham em direção à síntese. A propósito, penso na proposição de Gisele Brelete que, ao associar a forma sonata, comumente compreendida como a forma característica do primeiro movimento das sinfonias clássica e romântica, com a dialética de Hegel, conclui que pensamento e música em questão são estruturalmente semelhantes (Brelete, 1986, p. 211/220). Contrariamente, não há em Film Socialisme o esquema consagrado da dialética: passado (tese/tema), presente (novo tema/antítese), futuro (síntese). Não há esse esquema sequer em um movimento particular. Em Film Socialisme perpassa a ideia de que o futuro não decorre do passado, ou melhor, não cumpre as promessas de um projeto do passado. A história, ela mesma fica estagnada em um emaranhado de pequenas histórias (trilhas) que compõem sua matéria. Por exemplo, onde está o ouro de Moscou? Onde está o ouro de Odessa? As questões não são respondidas e a história não se desenvolve na mera sequencia temporal: passado, presente e futuro. 
Destarte, sob o parâmetro da organização da ação no tempo, Film Socialisme apresenta a seguinte estrutura: a) movimento um, filmado no navio, a ação transcorre no presente, dando-nos a sensação de ser um andamento rápido; b) movimento dois, filmado no posto; a ação também transcorre no presente, dando-nos a sensação de ser um andamento lento; c) movimento três, imagens dos lugares históricos e lendários, não há como decidir completamente se a ação está no presente, passado ou futuro, dando-nos a sensação de ser um andamento mais rápido do que o primeiro.

Não obstante, observando os eventos sonoros que constituem cada um dos referidos movimentos, tal como dispostos por Gabriel Hafner e François Musy, aprofundamos a interpretação sobre a macroforma de Film Socialisme. ${ }^{10} \mathrm{~A}$ primeira cena, Papagaios mudos em flash! Após esta imagem silenciosa, a músicafilme, irrompe no espaço deixado pelas palavras que não vieram. ${ }^{11} \mathrm{Em} \mathrm{Film}$ Socialisme, a música-filme é um dos eventos sonoros mais relevantes para a escuta. Primeiro porque ouvimos inteiramente suas frases iniciais, imbuindo-nos de sua lógica sistêmica; trata-se uma música tonal que incide em um contexto majoritariamente aleatório de organização sonora. Segundo porque a sua duração e incidência em cena é suficiente para que seja memorizada, ao contrário de outros eventos sonoros que incidem descritivamente e momentaneamente nas cenas. Terceiro porque ela é extra-diegética em um contexto que prevalecem estruturalmente eventos sonoros diegéticos. ${ }^{12}$

\footnotetext{
${ }^{10}$ Consta na ficha técnica que Gabriel Hafner e François Musy respondem pelo som do filme. Observa-se que não se usa o termo trilha, enfatizando a interpretação de que Godard recusa a existência de uma relação hierárquica entre som e imagem em sua poética.

${ }^{11}$ Emprego a expressão música-filme para evitar o emprego de outra que poderia gerar interpretações confusas, face a seu próprio apelo histórico, qual seja: música tema ou simplesmente tema. É de se conjecturar que a música em questão seja um solo para um som misto de viola fisarmônica e órgão, composta por Betty Olivero, compositora israelense, aluna de Bério, cujo nome é citado no encarte do DVD. Afinal, a referida compositora é também conhecida como uma virtuose de viola fisarmônica. Para escutá-la ir ao site oficial do filme.

12 Música diegética é aquela composta para ilustrar uma imagem cinematográfica em que existe uma fonte visível de emissão sonora (o piano de Sam, em Casablanca, ou Doris Day cantando, em o Homem que sabia demais). Música não diegética é a que é apresentada na tela sem a presença de uma fonte sonora (Rosa, 2003, p.97). Como veremos posteriormente, todos os sons de Film Socialisme, a maioria deles produzidos em fontes visíveis na cena, formam uma grande música que se confunde com o próprio filme.
} 
A música-filme perpassa todo o primeiro movimento, deixando-nos identificar suas frases iniciais e as respostas a estas frases compostas em variação por aumento. Relacionada tematicamente a ela, há uma outra, tocada em cordas, que incide em sequencias cênicas mais fragmentárias. No segundo movimento, não há música-filme. Em linhas gerais, temos um grande evento de rarefação sonora, vez ou outra interrompido por ruídos de câmera e músicas de caráter mais tradicional, de uma coloração estilística que vai do barroco ao romântico, incluindo-se aí a célebre Patética de Beethoven. No terceiro movimento, a músicafilme reaparece, porém, precedida de clusters que pontuam imagens da história.

Em uma palavra, tendo em conta a posição da música-filme, temos um autêntico $A / / B / / A^{\prime}$. A sensação de que escutamos uma tal forma é reforçada pelo segmentação da obra em seções, segundo o critério de adensamento e rarefação de texturas sonoras. Nesse caso, temos: a) primeiro movimento (A), uma curva ascendente do denso ao muito denso, bruscamente interrompida pelo silêncio; $b$ ) segundo movimento (B), rarefação, inserção mais tradicional de relações entre som e imagem; c) terceiro movimento ( $\left.A^{\prime}\right)$, nova curva ascendente do denso ao muito denso bruscamente interrompida pelo silêncio das palavras que encerram o filme - No Comment (Sem comentários).

Há de se perguntar se a sinfonia de Godard é também uma grande canção inscrita no tradicional $\mathrm{A} / / \mathrm{B} / / \mathrm{A}^{\prime}$. Do ponto de vista temporal e topológico, penso que sim. Pondero que a própria configuração da sensação auditiva de forma se dá mais pela relevância de um evento sonoro, qual seja, a música-filme, do que por fatores quantitativos de simetria. Por outro lado, mesmo reconhecendo falta de valor científico, evoco a opinião corrente de que o $2^{\circ}$ movimento de Film Socialisme é o mais demorado e monótono. Observando o quadro do Anexo II concluímos que a sensação não está apoiada na quantificação de eventos. A ausência da música-filme e a consequente interrupção do fluxo rítmico anterior provavelmente causam a sensação de monotonia. Entretanto, o efeito mais pitoresco e dramático do A//B//A' de Godard se dá no $3^{\circ}$ movimento, quando a música-filme configura o $A^{\prime}$. Nesse ponto, sabia-se que o filme iria findar, segundo 
uma proposição imagética até então pouco explorada: os vídeos. Em uma palavra, - A retornou como A' tanto mais pela semelhança musical do que pela dessemelhança de imagens e textos. Entre dois grandes movimentos, separados pela rarefação, o tempo foi e voltou ou simplesmente não passou.

Temporalmente e topologicamente, levando-se em consideração a posição e relevância da música-filme, a história contada por Godard não se moveu dialeticamente, como poderiam supor Hegel e Marx. O tempo parece sempre ter estado lá, como poderiam dizer os gregos antigos evocados nas cenas finais de Filme Socialisme: "Histórias, Democracia e Tragédia se casaram em Atenas sob Péricles e sob Sófocles. Um único filho, a guerra civil" (DVD, Cap.12). Nesse ponto, Godard parece ter concluído seu pensamento político; na ausência dos grandes esquemas explicativos, na ausência dos grandes projetos coletivos, resta o que sempre esteve aí: a luta fratricida.

\section{2- Paisagem sonora}

No texto "Film Socialisme: liberdade, igualdade e fraternidade", Arthur Mas e Matial Pisani procuram reconstituir os inúmeros fios de narrativa que se entrelaçam na obra de Godard, contrariando a opinião de que ela é uma colagem incompreensível de sons e imagens (Independência, 2010). Esses fios de narrativa, misturas de elementos de realidade e ficção, estabelecem um campo multivetorial de sentidos de aproximação entre público e obra. Nesse caso, não cabem ao olhar e à escuta perseguirem sentidos e significados na linearidade ou circularidade do tempo, como na situação descrita anteriormente, mas interagirem com blocos de signos cujos sentidos se revelam em instantes que condensam futuro, passado e presente (ekstasis), ${ }^{13}$ os quais podem formar linhas de compreensão de diversas amplitudes e profundidades, justamente, os referidos fios de narrativa. ${ }^{14}$

\footnotetext{
${ }^{13}$ A noção grega de ekstasis, qual seja, instante de condensação das dimensões temporais que revelam blocos de sentido é teorizada, sobretudo, na psicologia aristotélica (Aristóteles, 424 a 32, 2006) e, contemporaneamente na obra Ser e Tempo de Martin Heidegger (Heidegger, 1988, pr. 45). Segundo essa noção, o sentido/significado de um ente qualquer é dado por uma apreensão teleológica do presente e do passado, no futuro. Por exemplo,
} 
Não obstante a identificação anterior de que Film Socialisme possui forma ternária, seja sinfonia ou canção, a constatação da existência desses fios de narrativa permite aprofundar a compreensão de outro aspecto formal relevante. Como argumentado, é de se concluir que Film Socialisme descreve um transcurso circular que sugere a estaticidade de seu próprio desenvolvimento. Porém, no interior desse transcurso desenvolve-se uma dinâmica multivetorial de sentidos, que condensa na dimensão da presença intuições do futuro e do passado. Retomo um exemplo mencionado; não vimos apenas as escadarias de Odessa, mas evocamos seu passado e seu futuro pela lembrança fragmentária do filme de Einsenstein e pela imagem das crianças. Em uma palavra, Film Socialisme realizase como mimese da dinamicidade do mundo, visto e escutado por um sujeito fragmentário. Sua trilha corrobora esta interpretação, na medida em que compõe uma paisagem sonora.

Para interpretar Film Socialisme, considerando-o paisagem sonora, tomo este conceito na acepção de que ele inicialmente se refere a um complexo de sons referenciados que se mantém em unidade graças a uma estabilidade de textura. Porém, esta estabilidade abriga tensões implícitas ou, como quer Murray Schafer, um cone de tensões (Schafer, 1992, p. 90). Film Socialisme traz de um modo intencional e não naturalista a tensão que é inerente à vida biológica do som, qual seja, a tensão entre ser reconhecidamente proveniente de uma fonte e, ao mesmo tempo, constituir-se por uma tendência a eliminar a referencia de sua origem, configurando-se como objeto sonoro (Coradini \& Zampronha, 2005, p. 12).

Esta tensão parece ser estratégica para a proposição discursiva de Godard, posto que, a partir dela, sugere-se facilmente que significante e significado são dissociados. Eis o porque de os ruídos de captação de som e imagem serem propositadamente explícitos em Film Socialisme; a ambiguidade que decorre deste procedimento serve justamente para demonstrar que o som não é

um luthier sabe, ao intuir o futuro do aspecto, que uma madeira será boa ou não para fazer um instrumento. Desse modo, ele sabe o que é a madeira e o instrumento.

${ }^{14}$ No anexo III exponho em um quadro alguns signos inventariados por Arthur Mas e Matial Pisani. 
necessariamente articulado ao seu significado mais previsível. Por exemplo, o som constante na tomada externa do navio, embora seja claramente percebido como o som do roçar do vento no microfone, é também atribuído à imagem do navio no mar. O som dos vídeos antigos é ao mesmo tempo o som do vídeo (do som que está gravado na fita antiga de vídeo) e da personagem que nele fala. O som amador de alguns microfones é o som do próprio microfone e da voz do narrador. Além desses sons ambíguos, há os que são completamente deslocados de sua origem. É o caso dos gatinhos que pronunciam melopeias de papagaios.

Nessa mesma linha de sons ambíguos, incluo os sons ou procedimentos sonoros que decepcionam ou inibem a formação de expectativa. Qualquer frequentador de uma sala de cinema que possua sistema dolby digital, ${ }^{15}$ está habituado a perseguir o som pela sala. Geralmente, é de se esperar que o som descreva o percurso da disposição das caixas na sala ou execute movimentos de aproximação e afastamento, sincronizados aos movimentos das imagens. Em Film Socialisme definitivamente esses movimentos esperados não ocorrem. Antes disso. Os movimentos do som no espaço são exagerados e quase nunca parecem descrever uma ordem de transcurso pré-estabelecida. Desse modo, parecem ser produto de uma decisão arbitrária do compositor, a revelia de contribuírem ou não para a gênese ou afirmação de um significado imagético.

O recurso de acentuar um texto em detrimento de outro é, na maioria das vezes, evitado, para que nada pareça lógico. Nesse sentido, as estruturas polifônicas e politextuais configuram-se mais como sobreposições de ruídos do que, como efetivamente são, eventos sonoros intencionalmente organizados. Não há motivo aparente para que um evento esteja mais atrás ou mais à frente, ou de algum lado específico. É o caso dos textos de diversas línguas que são frequentemente escutados juntos. E também da sobreposição entre a música de banda e a música-filme no capítulo final. Definitivamente, não há relações de causa e efeito, como é de se conceitualmente imputar a uma paisagem sonora (Tragtenberg, 2008, p. 55). Há, em contrapartida, uma base de textura polifônica

\footnotetext{
${ }^{15}$ Dolby digital: formato de som que se utiliza de 5 canais separados (Lopes, 2004, p. 23).
} 
tensa; os sons ambíguos e deslocados, os procedimentos sonoros inesperados, acrescidos e estruturados pelo silêncio, formam uma espécie de cantochão de ruídos, que permanece como estrutura intencionalmente imperfeita, da qual se erguem outras vozes, que estão dentro e fora do filme.

Esta base tensa de textura polifônica estabelece a tonalidade afetiva de Film Socialisme. Sua imperfeição intencional distancia a obra do público, a ponto de a obra ser concebida como uma estrutura estranha. É oportuno o comentário. Curiosamente, em duas das seções de Film Socialisme que presenciei, pessoas se retiraram da sala na hora em que som e imagens ficaram granulados, supondo que o filme estivesse estragado. Ironia de Godard? A obra que mimetiza o mundo fragmentado fornece uma visão crítica de si mesma; e de seu estranhamento renova-se o olhar e a escuta do mundo ao redor.

Concomitantemente, a base tensa de textura polifônica sustenta outros eventos sonoros de Film Socialisme, eventos que, em sua maioria, podem ser compreendidos como procedimentos tradicionais de associação entre som e imagem, que escapam ao clichê para se configurarem como eventos de renovação poética. ${ }^{16}$ Destaco os perfeitos sincronismos de distorção de som e imagem, até a granulação de um e outro. Também os perfeitos des-sincronismos entre som e imagem, a ponto de vez ou outra serem no filme só som ou só imagem, numa completa acentuação de significado por negação. Sobre a mesma base sustentamse as anti-rimas semânticas, como a associação entre a Patética e a interrogação sobre a impossibilidade de programas políticos, feita pela "Família Martin". E também as alterações de rotação que acentuam o cromatismo de melodias que sugerem o desfalecimento interior dos protagonistas face ao impasse político e intelectual mundanos.

\footnotetext{
${ }^{16}$ Reforço a informação de que os eventos imagéticos e sonoros de Film Socialisme ocorrem como fragmentos que se repetem ao longo do tempo. O diretor nitidamente quer, com tal procedimento, argumentar que não há lógica aparente na "história" contada, posto que a linguagem falha ao conta-la. Destarte, sincronismos e des-sincronismos, rimas e anti-rimas são procedimentos poéticos que perpassam todo o conjunto de narrativas que constitui o filme.
} 
$\mathrm{Na}$ medida em que os eventos se sucedem, completa-se a textura característica da paisagem sonora de Film Socialisme. Parte essencial de sua estrutura formal, esta paisagem é completamente coerente com o propósito de Godard de privilegiar o tratamento de sons e imagens ante as narrativas tradicionais. Enfim, uma paisagem que em seu cerne abriga o acolhimento da imperfeição, o que facilita o reconhecimento de que Film Socialisme possui o forte apelo do estranhamento.

\section{Conclusão}

Tendo em conta a reflexão precedente, é de se concluir que Film Socialisme toma para si uma tarefa historicamente dedicada à música, a saber: resguardar-se como possibilidade de expressão onde propriamente a linguagem não alcança. Assim, Film Socialisme se estrutura como música, assumindo suas formas. Sobre a falibilidade dos signos fragmentados impõe-se a intuição da forma musical, que oferece uma perspectiva de organização dos eventos no tempo. Preserva-se desse modo a condição de possibilidade de produção do sentido. Ironia? As formas da música permitiram que Film Socialisme estruturasse narrativas sem necessariamente recorrer a um modo de pensar que a contemporaneidade colocou em descrédito.

Assim estruturado, Film Socialisme se impõe como uma obra atual, capaz de dialogar com sua época de incidência, mantendo-se constantemente, pela abertura de seu caráter artístico, uma origem do pensamento. O tempo irá dizer até que ponto respondemos ao apelo desta obra paradigmática, aceitando seu modo de significar o mundo. Mas parece fato que este apelo já se faça sentir no meio cinematográfico. É sabido que Film Socialisme não é pioneiro quanto à adoção estrutural de uma forma própria da música. Todavia, esse fato não o torna menos original e passível de reconhecido mérito. Film Socialisme faz valer a eficácia de sua poética, para a qual contribui o tratamento simples da relação entre música e imagem em todos os níveis. Por outro lado, configura-se promissor 
o terceiro sentido de compreensão e elaboração da música de filme, tal como mencionado na introdução deste artigo.

\section{Referências}

ARISTÓTELES. De Anima - Livros I/II/III. Apresentação, tradução e notas de Maria Cecília Gomes dos Reis. São Paulo: Editora 34 Ltda, 2006.

BADIOU, Alain. "Nota complémentaire sur um contemporain uso de Frege" In: Le Nombre er lês nombres. Paris: Seuil, 1990.

BLANCHETTE, Patrícia A. Frege's Conception Of Logic. New York: Oxford USA Professio, 2012.

BRELETE, Gisele. Tempo Histórico e Tempo Musical em Hegel - Revista Kriterion Departamento de Filosofia da FAFICH - ISSN - 0100 - 512 X. Belo Horizonte: UFMG, Resenha 76, Janeiro a Junho de 1986, pp. 211/220

CORADINI, Leandro Pedrotti \& ZAMPRONHA, Edson. Considerações sobre o Formalismo e o Referencialismo na Composição Musical Contemporânea, IN: ANPPOM - Décimo Quinto Congresso, 2005.

GODARD, J. L. Film Socialisme. (Site) In: http://www.rottentomatoes.com/m/ film_socialisme, postado em 2010.

GODARD, Jean-Luc. Film Socialisme. DVD - 101 min. França-Suíça: Imovision, 2010.

HEIDEGGER, Martin. Ser e Tempo. Trad. Márcia Sá Cavalcante Schuback. $1^{a}$ Ed. Rio de Janeiro: Ed. Vozes, 1988.

HEIDEGGER, Martin. A Caminho da Linguagem. Trad. Márcia Sá Cavalcante Schuback. $1^{\text {a }}$ Ed. Rio de Janeiro: Ed. Vozes, 2003.

LACAN, Jacques. O seminário sobre "A carta roubada" - in: Escritos - trad. Vera Ribeiro. Zahar: Rio de Janeiro, 1998.

LOBER, Kino. Film Socialisme. In: http://philosophynow.org/ issues/89/Film_Socialisme, postado em 2010.

LOPES, Adriana. Vocabulário para Cinema - Inglês/Português. São Paulo: SBS Editora, 2004.

MAS, Arthur \& PISANI, Martial. Film Socialisme: Liberdade, Igualdade e Fraternidade, Trad. Marcelo Rodrigues Souza. In: http://www.independencia.fr/revue/spip.php?article19, Publicado em 01/07/2010.

MONACO, James. How to Read a Film - The world of movies, media and multimedia. New York; Oxford: Oxford University Press, 2000. 
NIETZSCHE F. A Visão Dionisíaca do Mundo. São Paulo: Martins Fontes, 2006.

REPETTO, Bruna. Quando a música entra em cena. Porto Alegre: ediPUCRS, 2011.

ROGER, E. Film Socialisme. In: http://rogerebert.suntimes.com/apps/pbcs.dll /article?, postado em 08/06/2011.

ROSA, Ronel Alberti da. Música e Mitologia do Cinema - Na trilha de Adorno e Eisler. Ijuí: Editora Unijuí, 2003.

ROSSEAU, Jean-Jacques. Ensaio Sobre a Origem das Línguas - Col. Os Pensadores. São Paulo: Ed. Nova Cultural, 1999 p. 247/331.

SCHAFER, R. Murray. O Ouvido Pensante. Trad. Marisa Trench de O. Fonterrada, Magda R. Gomes da Silva; Maria Lúcia Pascoal. São Paulo: Ed. UNESP, 1992.

SCHOPENHAUER. O mundo como vontade e representação. Tradução de M. F. Sá Correia. Lisboa: Ed. Rés, 1969.

TOMÁS, Lia. Ouvir o Lógos. 1ª Ed. São Paulo: UNESP, 2002.

TRAGTENBerG, Livio. Música de Cena. São Paulo: Perspectiva, 2008.

VATTIMO, Gianni. Introdução a Heidegger. Trad. João Gama. Lisboa: Instituto Piaget, 1996.

\section{Anexo I}

\begin{tabular}{|c|c|}
\hline \multicolumn{2}{|l|}{ Ficha Técnica } \\
\hline Título & Film Socialisme (França, Suíça - 2010) \\
\hline $\begin{array}{l}\text { Títulos } \\
\text { Alternativos }\end{array}$ & Socialism / Socialisme / Film Socialism \\
\hline Gênero & Drama \\
\hline Duração & $101 \mathrm{~min}$ \\
\hline Tipo & Longa-metragem colorido \\
\hline Distribuidora & Imovision \\
\hline Produtoras & $\begin{array}{l}\text { Veja Film; Office Fédéral de la Culture; Télévision Suisse-Romande; La Ville de } \\
\text { Genève; Suissimage; Fondation Vaudoise; Fonds Regio Films; Wild Bunch; Canal + }\end{array}$ \\
\hline $\begin{array}{l}\text { Diretor e } \\
\text { Roteirista }\end{array}$ & Jean-Luc Godard \\
\hline Elenco & $\begin{array}{l}\text { Christian Sinniger (o pai); Jean-Marc Stehlé (Otto Goldberg); Patti Smith (a cantora); } \\
\text { Robert Maloubier (homem); Alain Badiou (filósofo); Nadège Beausson-Diagne } \\
\text { (Constance); Élisabeth Vitali (Jornalista da FR3); Eye Haidara (Cinegrafista da FR3); } \\
\text { Quentin Grosset (Lucien); Olga Riazanova (agente secreto russo); Marine Battagia; } \\
\text { Marie-Christine Bergier; Agatha Couture; Dominique Devals; Mathias Domahidy; } \\
\text { Gulliver Hecq; Lenny Kaye; Bernard Maris; Elias Sanbar; Louma Sanbar; Maurice } \\
\text { Sarfati }\end{array}$ \\
\hline Fotógrafos & Fabrice Aragno; Paul Grivas \\
\hline $\begin{array}{l}\text { Produtora } \\
\text { Executiva }\end{array}$ & Ruth Waldburger \\
\hline $\begin{array}{l}\text { Supervisor de } \\
\text { Producão }\end{array}$ & Jean-Paul Battaggia \\
\hline $\begin{array}{l}\text { Departamento } \\
\text { de Som }\end{array}$ & Gabriel Hafner; François Musy \\
\hline
\end{tabular}




\begin{tabular}{|c|c|}
\hline $\begin{array}{l}\text { Departamento } \\
\text { de Câmera e } \\
\text { Elétrica }\end{array}$ & Paul Grivas \\
\hline Colaboradores & Fabrice Aragno; Anne-Marie Miéville \\
\hline Fonte & http://epipoca.com.br/filmes_ficha.php?idf = 23430 \\
\hline Textos & $\begin{array}{l}\text { W. Benjamin; J. Derrida; JP. Curnier; R. Dubillard; H. Arendt; O. Bismarck; JP. } \\
\text { Sartre; L. Brunschwig; J. Giraudoux; J. tardieu; C. Peguy; L. Aragon; S. Rullac; H. } \\
\text { Bergson; G. Bernanos; D. De Rougemont; C. Wolff; R. Korsakov; F. Braudel; C. } \\
\text { Simon; N. Gabler; L. Pirandello; P. Ricouer; S. Beckett; A. Malraux; C. Levi-Strauss; J. } \\
\text { Conrad; W. Shakespeare; M. Heidegger; LA Rochefoucauld; W. Goethe; C. } \\
\text { Malaparte; J. Genet; Z. Oldenbourg }\end{array}$ \\
\hline Audios & $\begin{array}{l}\text { Betty Olivero; Arvo Pärt; Anouar Brahem; Tomasz Stanko; Bernd Alois } \\
\text { Zimmermann; Giya Kancheli; Werner Pirchner; E. Busch; Thierry Machuel; Ludwig } \\
\text { Van Beethoven; Chet Baker }\end{array}$ \\
\hline
\end{tabular}

\section{Anexo II}

\begin{tabular}{|c|c|c|c|}
\hline \multicolumn{4}{|c|}{ Relações entre eventos imagéticos e sonoros de Film Socialisme. } \\
\hline Mov. 1 & Imagem & Evento Sonoro & $\begin{array}{l}\text { Interpretação da relação } \\
\text { entre imagem e evento } \\
\text { sonoro. }\end{array}$ \\
\hline \multirow[t]{3}{*}{ Cena 1} & 1) Papagaios em flash. & 1) Silêncio. & $\begin{array}{l}\text { Marco inicial do filme: } \\
\text { existência paradoxal de uma } \\
\text { instancia de } \\
\text { incomunicabilidade ou de } \\
\text { comunicação estendida. }\end{array}$ \\
\hline & $\begin{array}{l}\text { 2) Tomadas externas e } \\
\text { internas do navio. }\end{array}$ & $\begin{array}{l}\text { 2) Música-filme. Ruídos de } \\
\text { captação do vento e das } \\
\text { coisas do navio. }\end{array}$ & $\begin{array}{l}\text { Sugestão de que a realidade } \\
\text { filmada possui um aspecto de } \\
\text { coisa. }\end{array}$ \\
\hline & $\begin{array}{l}\text { 3) Pessoas dançando na } \\
\text { discoteca. }\end{array}$ & $\begin{array}{l}\text { 3) Som distorcido até a } \\
\text { completa granulação. }\end{array}$ & $\begin{array}{l}\text { Inclusão dos ruídos na obra } \\
\text { de arte (filme). } \\
\text { Dessacralização do estético. }\end{array}$ \\
\hline \multirow[t]{2}{*}{ Cena 2} & $\begin{array}{l}\text { 1) Pessoas filmam e } \\
\text { fotografam. }\end{array}$ & 1) Música-filme. & $\begin{array}{l}\text { Caráter corriqueiro do filmar } \\
\text { e fotografar em oposição ao } \\
\text { caráter dramático da música. } \\
\text { Ambos os caracteres são } \\
\text { realçados. }\end{array}$ \\
\hline & 2) Gatinhos. & 2) Melopeia de papagaios. & $\begin{array}{l}\text { A linguagem dissociada de } \\
\text { qualquer fundamento na } \\
\text { realidade, até mesmo com } \\
\text { quem a pronuncia. }\end{array}$ \\
\hline \multirow[t]{2}{*}{ Cena 3} & $\begin{array}{l}\text { 1) Legenda quase que } \\
\text { autônoma em relação ao } \\
\text { texto falado. }\end{array}$ & 1) Polifonia de narrativas. & $\begin{array}{l}\text { Reforça a ideia de dissociação } \\
\text { entre linguagem e realidade. }\end{array}$ \\
\hline & 2) Bonecas. & 2) Canção ariosa. & $\begin{array}{l}\text { Um significado reforça o } \\
\text { outro. Bonecas e canção são } \\
\text { referência direta a URSS. }\end{array}$ \\
\hline Cena 4 & $\begin{array}{l}\text { 1) Imagens do } \\
\text { significante ouro. }\end{array}$ & $\begin{array}{l}\text { 1) O som da narrativa de } \\
\text { Constance passeia nos } \\
\text { planos bem definidos } \\
\text { (frente, fundo, direita e } \\
\text { esquerda), realçando }\end{array}$ & $\begin{array}{l}\text { O ouro é um forte significante } \\
\text { do Capitalismo, reforçado } \\
\text { pela concentração de } \\
\text { significados dos eventos } \\
\text { sonoros em questão. }\end{array}$ \\
\hline
\end{tabular}




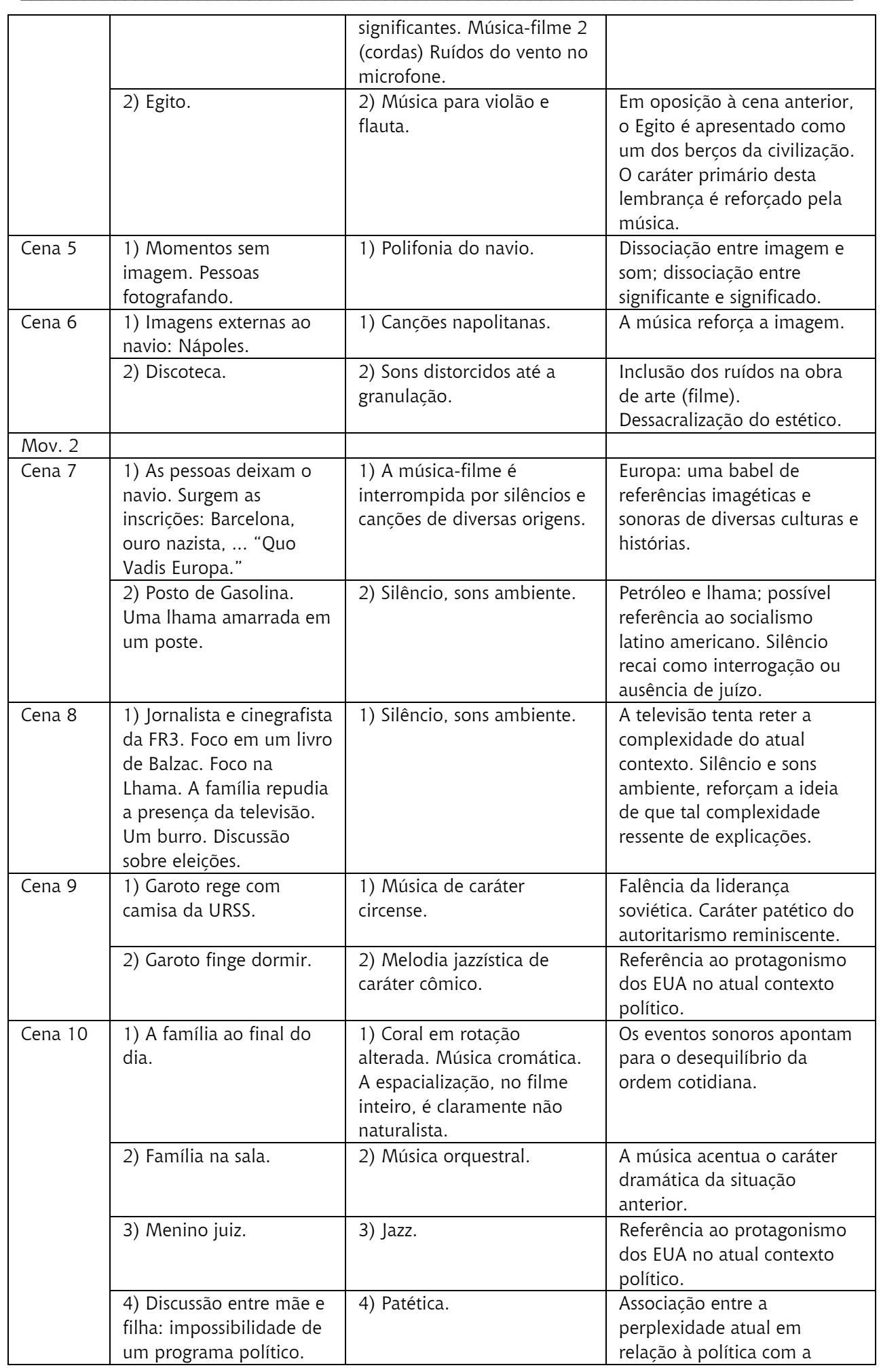




\begin{tabular}{|c|c|c|c|}
\hline & & & $\begin{array}{l}\text { perplexidade experimentada } \\
\text { por Beethoven. A música } \\
\text { empresta dramaticidade à } \\
\text { situação descrita. }\end{array}$ \\
\hline \multicolumn{4}{|l|}{ Transição } \\
\hline \multirow[t]{4}{*}{ Cena 11} & $\begin{array}{l}\text { 1) Garoto na escada, } \\
\text { pintando um Renoir. A } \\
\text { textura de cores do } \\
\text { quadro e do filme se } \\
\text { tornam a mesma. }\end{array}$ & $\begin{array}{l}\text { 1) Música-filme. Coro. } \\
\text { Silêncio. }\end{array}$ & $\begin{array}{l}\text { A síntese entre arte e } \\
\text { realidade sugerida pelas } \\
\text { imagens é reforçada pela } \\
\text { síntese dos elementos } \\
\text { sonoros trabalhados } \\
\text { anteriormente. }\end{array}$ \\
\hline & $\begin{array}{l}\text { 2) Inscrição na tela: } \\
\text { Palestina. }\end{array}$ & $\begin{array}{l}\text { 2) Cluster. Silêncio. } 2 \\
\text { clusters. }\end{array}$ & $\begin{array}{l}\text { O caráter suspensivo dos } \\
\text { eventos sonoros reforçam a } \\
\text { ideia de que a situação da } \\
\text { Palestina não está resolvida. }\end{array}$ \\
\hline & $\begin{array}{l}\text { 3) Inscrição na tela: “Nos } \\
\text { Humanités". Vídeos dos } \\
\text { lugares. }\end{array}$ & $\begin{array}{l}\text { 3) Silêncio intercalado de } \\
\text { Cluster em tempo não } \\
\text { regular. Polifonia de textos e } \\
\text { música percutida distribuída } \\
\text { nos planos sonoros. }\end{array}$ & $\begin{array}{l}\text { A diversidade da realidade } \\
\text { representada pela diversidade } \\
\text { das narrativas imagéticas e } \\
\text { sonoras. }\end{array}$ \\
\hline & $\begin{array}{l}\text { 4) Referências imagéticas } \\
\text { à música. }\end{array}$ & 4) Canções. & $\begin{array}{l}\text { Música: ausência de } \\
\text { linguagem? Excesso de } \\
\text { linguagem? }\end{array}$ \\
\hline \multicolumn{4}{|l|}{ Mov. 3} \\
\hline \multirow[t]{5}{*}{ Cena 12} & 1) Vídeos de lugares. & 1) Canções. & $\begin{array}{l}\text { As canções delimitam as } \\
\text { identidades dos lugares. }\end{array}$ \\
\hline & 2) Holocausto. & 2) Texto bíblico de Isac. & $\begin{array}{l}\text { Reforça-se a ideia da } \\
\text { presença do "sacrifício" na } \\
\text { história. }\end{array}$ \\
\hline & $\begin{array}{l}\text { 3) Escadarias de Odessa. } \\
\text { Encouraçado. }\end{array}$ & $\begin{array}{l}\text { 3) Cluster. Música-filme. } \\
\text { Música de banda somada à } \\
\text { música-filme. Conclusão das } \\
\text { músicas-filme } 1 \text { e } 2 \text {. } \\
\end{array}$ & $\begin{array}{l}\text { Referência à relação entre } \\
\text { cinema e realidade. A música } \\
\text { reforça o caráter dramático } \\
\text { desta relação. }\end{array}$ \\
\hline & 4) Navio. & 4) Politextualidade. & $\begin{array}{l}\text { Retorno à imagem inicial. A } \\
\text { civilização à deriva, em sua } \\
\text { própria diversidade. }\end{array}$ \\
\hline & 5) “No comment." & 5) Silêncio. & $\begin{array}{l}\text { Retorno ao marco inicial do } \\
\text { filme: existência paradoxal de } \\
\text { uma instancia de } \\
\text { incomunicabilidade ou de } \\
\text { comunicação estendida. }\end{array}$ \\
\hline
\end{tabular}

\section{Anexo III}

\begin{tabular}{|l|l|}
\hline \multicolumn{2}{|l|}{ Signos que unem diferentes sentidos de interpretação no emaranhado de narrativas de Film Socialisme. } \\
\hline Coisas & $\begin{array}{l}\text { Alguns objetos tais como o relógio e a máquina de fotografar são recorrentes nos } \\
\text { três movimentos, constituindo polos de unidade em torno dos significados que } \\
\text { encampam. }\end{array}$ \\
\hline $\begin{array}{l}\text { Documentários } \\
\text { e vídeos. }\end{array}$ & $\begin{array}{l}\text { Um dos principais é o do cineasta Daniel Pollet, responsável pela cena em que o } \\
\text { mar é visto através de uma cerca de arame farpado, que representa a }\end{array}$ \\
\hline
\end{tabular}




\begin{tabular}{|l|l|}
\hline & impossibilidade de filmar a Palestina. \\
\hline O ouro & $\begin{array}{l}\text { História real e ficcional do ouro de Moscou que justifica a presença dos } \\
\text { personagens identificados no } 1^{\circ} \text { movimento do filme. Atrás do ouro de Moscou, a } \\
\text { câmera realiza um verdadeiro panorama de fragmentos da história do capitalismo e } \\
\text { do socialismo. }\end{array}$ \\
\hline Canalhas & $\begin{array}{l}\text { "Hoje o que mudou é que os canalhas são sinceros." Referência ao criminoso de } \\
\text { guerra Richard Christmann que em Film Socialisme assume diversas personalidades } \\
\text { nos três movimentos, inclusive, a de Otto Goldberg, suposto responsável pelo } \\
\text { sumiço do ouro. }\end{array}$ \\
\hline Odessa & $\begin{array}{l}\text { A parada em Odessa está ligada à lembrança do Encouraçado Potemkin e da } \\
\text { célebre cena do massacre nos degraus da escada Richelieu. Mas essa lembrança } \\
\text { retorna em Film Socialisme de uma maneira inédita. Ás imagens de Eisenstein, o } \\
\text { cineasta opõe aquela de um grupo turístico visitando os lugares da revolta de } \\
\text { 1905. Sobreposição de dois clichês do mesmo monumento, na qual o mito } \\
\text { revolucionário se submete à agência de viagem. }\end{array}$ \\
\hline Histórias & $\begin{array}{l}\text { Articulações entre as Histórias Antiga e Contemporânea. Nessa trilha, há } \\
\text { imbricamentos entre ficção e realidade, quando, por exemplo, Godard reporta a } \\
\text { personagens da resistência francesa, como é o caso da "Família Martin". }\end{array}$ \\
\hline Palavras & $\begin{array}{l}\text { Godard não perde a oportunidade de referir-se aos seus detratores. "No } \\
\text { Comment", expressão que encerra o filme. }\end{array}$ \\
\hline Animais & $\begin{array}{l}\text { Presença de animais em lugares inusitados. Evidentemente os animais assumem o } \\
\text { papel de símbolos. Lhama no posto de gasolina, provavelmente uma referência à } \\
\text { América Latina. Burrinho carregando televisão: Palestina. }\end{array}$ \\
\hline Lugares & $\begin{array}{l}\text { Nápoles, Barcelona, Palestina, Egito, Hellas, Odessa. Na ficção, lugares por onde } \\
\text { teria passado o ouro de Moscou. Na realidade, referências a conflitos históricos do } \\
\text { capitalismo e do socialismo. }\end{array}$ \\
\hline
\end{tabular}

